\title{
CURRENT STRATEGIES FOR ARTICULAR CARTILAGE REPAIR
}

\author{
Redman S. N., Oldfield S. F. and Archer C. W. \\ CITER (Cardiff Institute of Tissue Engineering and Repair), Cardiff School of Biosciences, Museum Avenue, Cardiff,
} CF10 3US, Wales, UK

\begin{abstract}
Defects of articular cartilage that do not penetrate to the subchondral bone fail to heal spontaneously. Defects that penetrate to the subchondral bone elicit an intrinsic repair response that yields a fibrocartilaginous repair tissue which is a poor substitute for hyaline articular cartilage. Many arthroscopic repair strategies employed utilise this intrinsic repair response to induce the formation of a repair tissue within the defect. The goal, however, is to produce a repair tissue that has the same functional and mechanical properties of hyaline articular cartilage. To this end, autologous osteochondral transfer can provide symptomatic relief. This technique involves the excision of healthy cartilage plugs from 'non-load bearing' regions of the joint for implantation into the defect. Cell based transplantation methods currently involve the transplantation of expanded autologous chondrocytes to the defects to form a repair tissue. This technique again involves the excision of healthy cartilage from the joint for expansion. Current research is exploring the potential use of mesenchymal stem cells as a source for tissue engineering, as well as the combination of cells with biodegradable scaffolds. Although current repair strategies improve joint function, further research is required to prevent future degeneration of repair tissue.
\end{abstract}

Key words: Cartilage Repair, Articular Cartilage, Mesenchymal Stem Cells, Cartilage Defects, Chondrocyte Plasticity.

Address for correspondence:

Prof. Charles Archer,

Cardiff School of Biosciences,

Museum Avenue,

Cardiff,

Wales, CF10 3US

Tel: +44(0)2920875206

Fax: +44(0)2920874594

E-mail: archer@cardiff.ac.uk

\section{Introduction}

Articular cartilage has a poor intrinsic capacity for repair. There are two major problems that need to be addressed in repair of articular cartilage. The first is to fill the defect void with a tissue that has the same mechanical properties as articular cartilage. The second is to promote successful integration between the repair tissue and the native articular cartilage. Even a small defect caused by mechanical damage will fail to heal and degenerate over time progressing to the debilitating condition of osteoarthritis. This review will aim to discuss the intrinsic repair response of articular cartilage, in the absence of vascular and neural supply, and examine the procedures currently employed to promote articular cartilage repair.

\section{Cartilage Defects}

\section{Partial Thickness Defects}

Partial thickness defects of articular cartilage resemble the clefts and fissures observed during the initial stages of osteoarthritis. Defects of this nature in mature tissue do not heal spontaneously. This failure is thought to be due to the fact that they do not penetrate to the subchondral bone and so, do not have access to the progenitor cells of the bone marrow space (Fig. 1A). It has been shown that in a foetal lamb model, spontaneous repair of a superficial defect does occur with no fibrous scar and restoration of the zonal organisation of articular cartilage (Namba et al., 1998). Whether this is true repair, or 'void filling' as growth occurs is open for debate. In mature tissue, a limited repair process does take place in response to the trauma within the tissue immediately adjacent to the site of the defect. The nature of this repair response has been investigated and it has been observed that the cells adjacent to the wound margins undergo cell death. After twenty-four hours, however, there is an increase in cell proliferation or chondrocyte cluster formation. Concurrent with this proliferation is also an increase in matrix synthesis and catabolism. This response is short lived and there is failure to repair the defect (Mankin, 1982). It has also been observed that cells can be induced to migrate from the synovium across the articular surface to the lesion and under the influence of growth factors can fill the defect with a repair tissue (Hunziker, 2001; Hunziker and Rosenberg, 1996). In the absence of a fibrin matrix and mitogenic factors, these 'synovial cells' fail to fill the defect void due in part to the anti-adhesive properties of proteoglycans especially the small leucine rich proteoglycans such as biglycan, decorin and fibromodulin (Hunziker and Rosenberg, 1996). Thus, it 


\section{A: partial thickness defect}

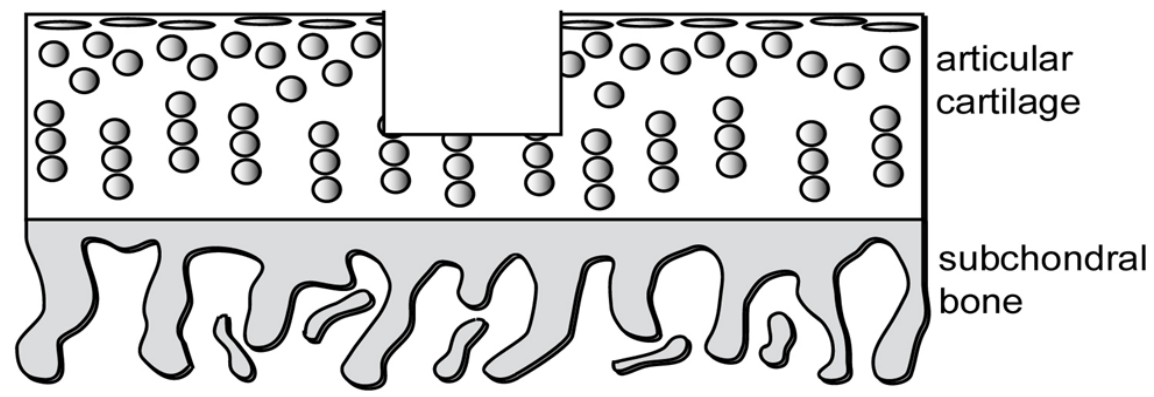

\section{B: full thickness defect}

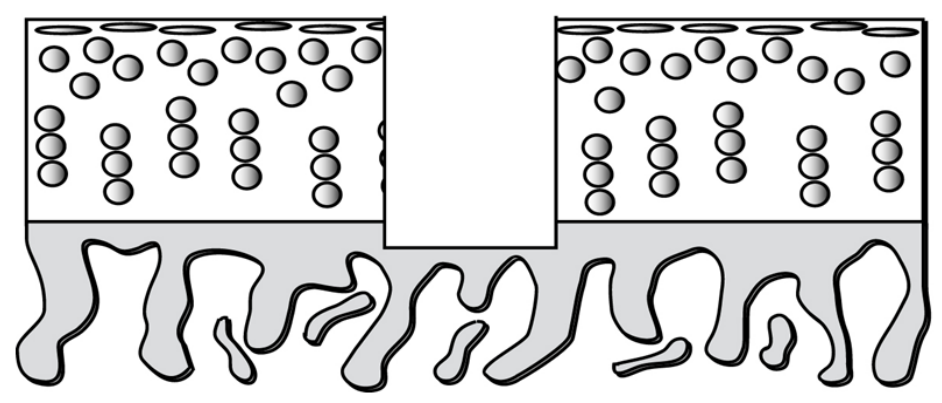

Figure 1. Diagram illustrating a partial thickness focal defect in articular cartilage (A) and a full thickness defect that penetrates to the subchondral bone (B).

is not only the absence of access to the bone marrow cells that prevents the repair of partial thickness defects, there are clearly other mechanisms involved that remain to be fully elucidated.

\section{Full Thickness Defects}

Full thickness defects pass through the zone of calcified cartilage and penetrate the subchondral bone thereby gaining access to the cells that reside in the bone marrow space including the mesenchymal stem cells located therein (Fig. 1B). The repair response elicited by this type of defect results in the formation of a fibrocartilaginous tissue in the defect void. The events leading up to the formation of the repair tissue in a rabbit model have been characterised (Shapiro et al., 1993), indicating an immediate response to penetration of the subchondral bone in a full thickness defect with, in some cases, formation of hyaline-like articular cartilage. This repair tissue is a poor substitute for articular cartilage and, with time, there is marked degeneration of the repair tissue and continued degeneration of the native articular cartilage. It has been noted (Shapiro et al., 1993) that during this process, the tissue adjacent to the wound margins becomes necrotic and apart from occasional chondrocyte cluster formation, little to no remodelling occurs. It was also noted that the empty lacunae observed in the native tissue at the wound margins were not filled by either native migrating chondrocytes or mesenchymal cells from the defect void. By light microscopy, continuity between the native and repair tissue was observed but polarised light microscopy revealed no true integration of the two matrices and also revealed frequent regions of discontinuity. Although the outcome of the natural repair response to full thickness defects is poor, many operative procedures to alleviate joint pain are based upon this mechanism of repair.

\section{Repair Strategies}

\section{Arthroscopic Repair Procedures}

Arthroscopic lavage and debridement are often used to alleviate joint pain. Lavage involves irrigation of the joint during arthroscopy. This rinsing of the joint appears to alleviate pain although the mechanism for this is unclear (Livesley et al., 1991). The procedure may remove debris from the joint space thereby alleviating pain. Debridement is the arthroscopic removal of damaged tissue from the joint, which has also been shown to alleviate pain and when used in conjunction with lavage, pain relief appears to last longer (Chang et al., 1993). Both of these procedures are used routinely to alleviate joint pain and have been shown to be successful in treating the early stages of osteoarthritis (Jackson and Dieterichs, 2003; Shannon et al., 2001). Both lavage and debridement, however, do not induce repair of articular cartilage and a recent study has demonstrated that pain relief observed following debridement and lavage procedures may be no more than a placebo effect following surgery (Moseley et al., 2003).

Many arthroscopic procedures used to induce repair of articular cartilage take advantage of the intrinsic repair response, observed upon penetration of the subchondral bone in full thickness defects. These techniques include 
the following; abrasion arthroplasty, Pridie drilling and microfracture. Abrasion arthroplasty uses an automated burr to access the vasculature and is used in conjunction with debridement (Akizuki et al., 1997; Singh et al., 1991). Pridie drilling stimulates bleeding by drilling the subchondral bone (Beiser and Kanat, 1990; Insall, 1974). Microfracture involves the debridement of damaged tissue down to the subchondral bone which is then perforated by small awls, approximately $2-3 \mathrm{~mm}$ apart, to induce bleeding (Sledge, 2001). These techniques rely upon the formation of a blood clot that as described previously, will form a fibrous repair tissue. The clinical outcome of these procedures is varied, which is due, in part, to the unpredictable nature of the repair tissue formed, in addition to the age and activity levels of the patient (Hunt et al., 2002; Johnson, 2001; Steadman et al., 2003).

\section{Soft Tissue Grafts}

Soft tissue grafts involving the transplantation of periosteum and perichondrium to full thickness defects of articular cartilage have been used extensively in animal models and human clinical trials. Results have been varied although hyaline-like tissue has been reported. It has been shown that there is no significant difference between repair tissue formed from perichondrium or periosteum (CarranzaBencano et al., 1999). Periosteum, however, is more readily available for transplantation and, therefore, more widely used.

Periosteum has chondrogenic potential as demonstrated during development and fracture repair (O’Driscoll, 1999). The chondrogenic potential of periosteum is attributed to chondrocyte precursor cells in the cambial layer. Periosteum comprises the cambium layer that lies adjacent to the bone, and a fibrous layer. In vitro studies have shown that chondrocyte differentiation occurs in the juxta-osseous region of the cambium layer and progresses towards the fibrous layer, however, the fibrous layer does not become cartilaginous. Neocartilage growth is appositional, away from the fibrous layer, suggesting that chondrocyte precursor cells reside in the juxta-fibrous portion of the cambium layer (Ito et al., 2001). The use of periosteum to repair full thickness defects of articular cartilage experimentally involves first the creation of a full thickness defect of $4 \mathrm{~mm}$ diameter, and the removal of $1-2 \mathrm{~mm}$ of subchondral bone. The periosteal graft is then implanted into the defect with the cambial layer facing upwards towards the articular surface, the graft is held in place by fibrin glue (CarranzaBencano et al., 2000). The depth of the defect is thought to be critical to prevent articulation of the cambial layer with the opposing joint surface until matrix has formed (O'Driscoll, 1999). There is much debate as to the orientation of the cambial layer, whether it should face the joint space or the subchondral bone.

There are also two potential cell sources during this repair procedure, the periosteal chondrocyte precursor cells and the mesenchymal stem cells derived from the subchondral bone that is debrided prior to transplantation. It has been shown in a study using rabbits that only $33 \%$ of cases had repair tissue derived solely from the transplanted periosteum. The remaining $67 \%$ had repair tissue derived from both the transplanted tissue and the bone marrow mesenchymal stem cells (Zarnett and Salter, 1989). Clinically, it has been demonstrated that age and the use of continuous passive motion post-operatively are important factors in the successful outcome of periosteal transplantation (Alfredson and Lorentzon, 1999; Korkala and Kuokkanen, 1995; Lorentzon et al., 1998).

\section{Osteochondral Transfer}

Osteochondral transplantation of autogenic and allogeneic tissue has been widely used to treat predominately large osteochondral defects. Allogeneic material derived from cadaveric donors has been used to treat osteochondral defects with varying degrees of success (Czitrom et al., 1986). It has been demonstrated experimentally that fresh tissue is more successful than frozen tissue in terms of cell death and mechanical stability (Tomford et al., 1992). Despite the immunologically privileged position of articular cartilage, an immune response is still a potential problem with this approach (Langer et al., 1978; Stevenson, 1987). This technique has been widely employed with functional and symptomatic joint improvement. Whilst allogeneic osteochondral transplantation has been shown to benefit large osteochondral defects, autogenous osteochondral transplantation has been used to treat smaller full thickness defects.

Autologous osteochondral grafts involve the removal of cylindrical plugs of osteochondral tissue from nonload bearing regions of the articular cartilage, such as the femoral trochlear groove, and are transplanted to the debrided full depth defect (fig. 2). This procedure can be carried out either on an open joint or by arthroscopy (Hangody et al., 1997). Osteochondral transfer is most commonly referred to as 'MosaicPlasty ${ }^{\mathrm{TM}}$ ' (Smith \& Nephew) (Hangody et al., 1998) or OATS ${ }^{\mathrm{TM}}$ ' (Arthrex) (Bobic, 1999). Results have shown decreased pain and improved joint function and have been shown to be most successful for small and medium sized full-thickness defects (Hangody et al., 2004; Jakob et al., 2002). The questions remain, however, as to the viability of the chondrocytes from the donor tissue following the excision of the plug from the joint, whether tissue derived from a non-load bearing source can withstand the stress of a load-bearing area and the extent of donor site morbidity.

There have been very few studies into the viability at the margins of the osteochondral plug. A recent study, comparing two different methods of harvesting the plug has highlighted the issue of chondrocyte viability post harvest (Evans et al., 2004). Chondrocyte death at the margins of the osteochondral plug may lead to degeneration of the tissue and failure of the graft. The inevitable spaces that form between the grafts and the loss of chondrocyte viability from the margins of the plugs is a hindrance to lateral integration of the graft and recipient tissue which may also lead to the degeneration of the graft over time. There have also been very few studies into donor site morbidity associated with osteochondral transfer. Firstly, viability of the chondrocytes adjacent to the harvest sites must be considered, as cell death at the wound margins may again 


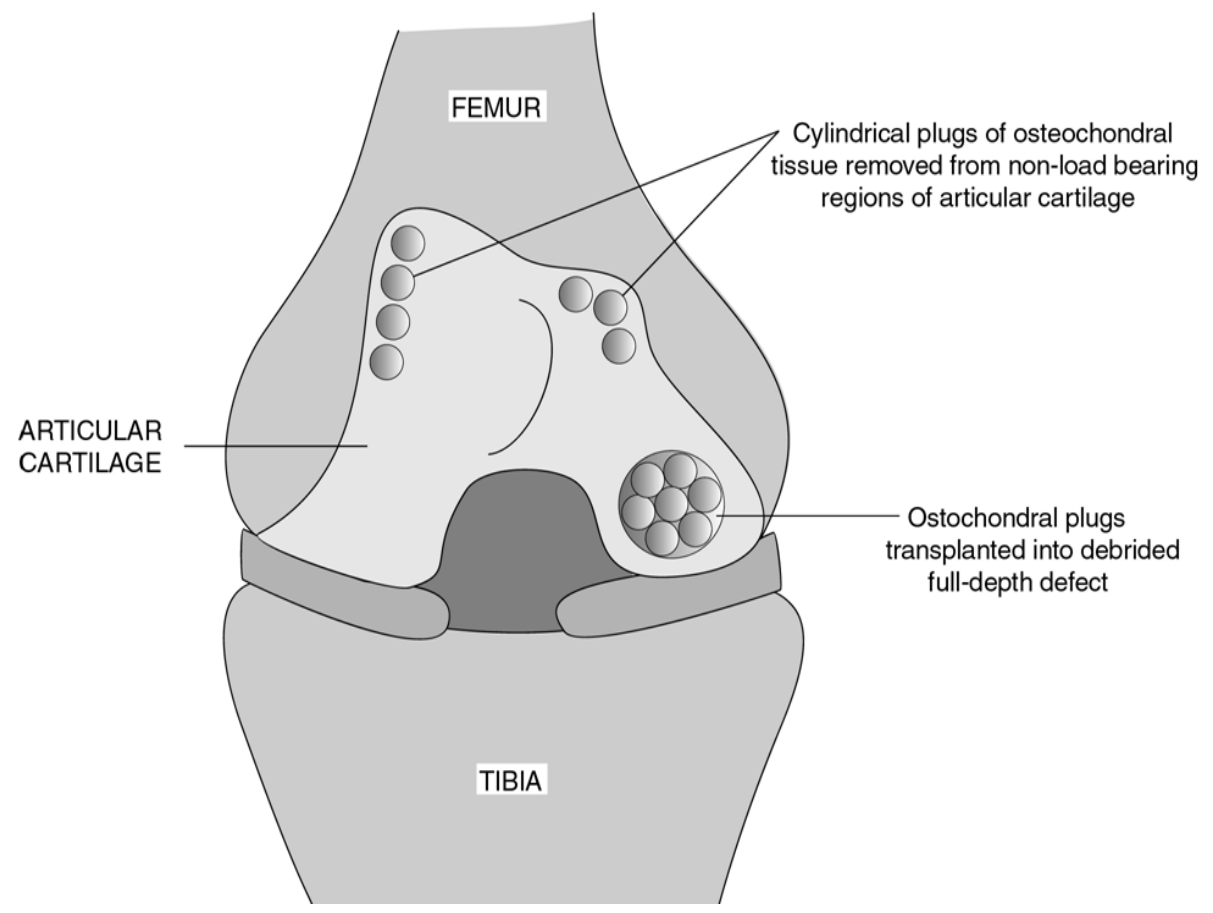

Figure 2. Schematic diagram illustrating the steps involved in osteochondral transfer.

lead to degeneration of the tissue over time. Secondly, it is assumed that a cartilaginous repair tissue will form in the void (again this relies upon the formation of a blood clot that will form a fibrous tissue), however, fibrocartilage hypertrophy and a lack of fibrocartilaginous regrowth have both been reported and associated with increased stiffness of the joint (Ahmad et al., 2002; LaPrade and Botker, 2004). The grafts are harvested from 'non-load bearing' regions of the joint. This harvest site is also contentious and it has been demonstrated that none of the harvest regions investigated in a study by Simonian et al., were shown to be truly non-load bearing, which may also have an impact upon the issue of donor site morbidity (Simonian et al., 1998).

\section{Cell Transplanation Based Repair}

\section{Autologous Chondrocyte Transplantation}

Autologous chondrocyte transplantation in humans (ACI) was first described by Brittberg et al., (1994) and recently reviewed by Brittberg (1999). The procedure involves the excision of a healthy biopsy by arthroscopy from a nonload bearing region of the articular cartilage. The chondrocytes are then released by enzymatic digestion and expanded in culture. A second procedure is then performed by arthrotomy. The defect is debrided back to the healthy cartilage but not to the subchondral bone. A periosteal graft is taken from the medial tibia, sutured over the defect; and cultured autologous chondrocytes are then injected under the periosteal flap (fig. 3). Results obtained showed reduced pain and restored joint function in many of the patients. Upon histological analysis of biopsies taken, it was shown that the repair tissue of 11 out of 15 patients with femoral defects were hyaline-like in nature, with only 1 out of 7 patellar defect patients showed hyaline-like repair tissue. This result indicated that the procedure maybe beneficial to treat femoro-tibial defects (Brittberg et al., 1994). It has been demonstrated, however, in a canine model that there was no significant difference between the repair tissue of treated and untreated defects indicating that the transplanted de-differentiated chondrocytes did not contribute to the repair response observed (Breinan et al., 1997). In a more recent study by Breinan (2001), changes in the composition of reparative tissue following ACI in the canine model over time was evaluated and compared to previous findings. In comparison to control groups, significantly more reparative tissue predominantly consisting of hyaline cartilage with some articular cartilage formation was observed in ACI treated lesions at 3 months following treatment. Results obtained over longer time periods showed no significant benefits of ACI between experimental and control groups. Autologous chondrocyte transplantation, however, is used in clinical practice with a number of clinical studies demonstrating satisfactory results. Clinical findings by Minas (1998), of patients treated for cartilage defects using ACI 12-24 months following surgery revealed that after 12 months, $72 \%$ of patients showed improved function and enhanced quality of life, which was sustained or improved after 24 months. In a 3 year follow-up investigation, Micheli, (2001), reported overall improvement in the knee condition and functional outcome in $84 \%$ of patients. Results of the longest ongoing clinical study demonstrates satisfactory results at $2-9$ years in $80 \%$ of patients, with $90 \%$ of patients with femoral condylar defects showing good results (Peterson et al., 2000).

It must be borne in mind that there are three potential cell sources in the ACI procedure; the transplanted chondrocytes, chondrocytes precursor cells from the grafted periosteum and a third source from the mesenchymal stem cells derived from the subchondral bone marrow space. Although ACI can offer long-term 


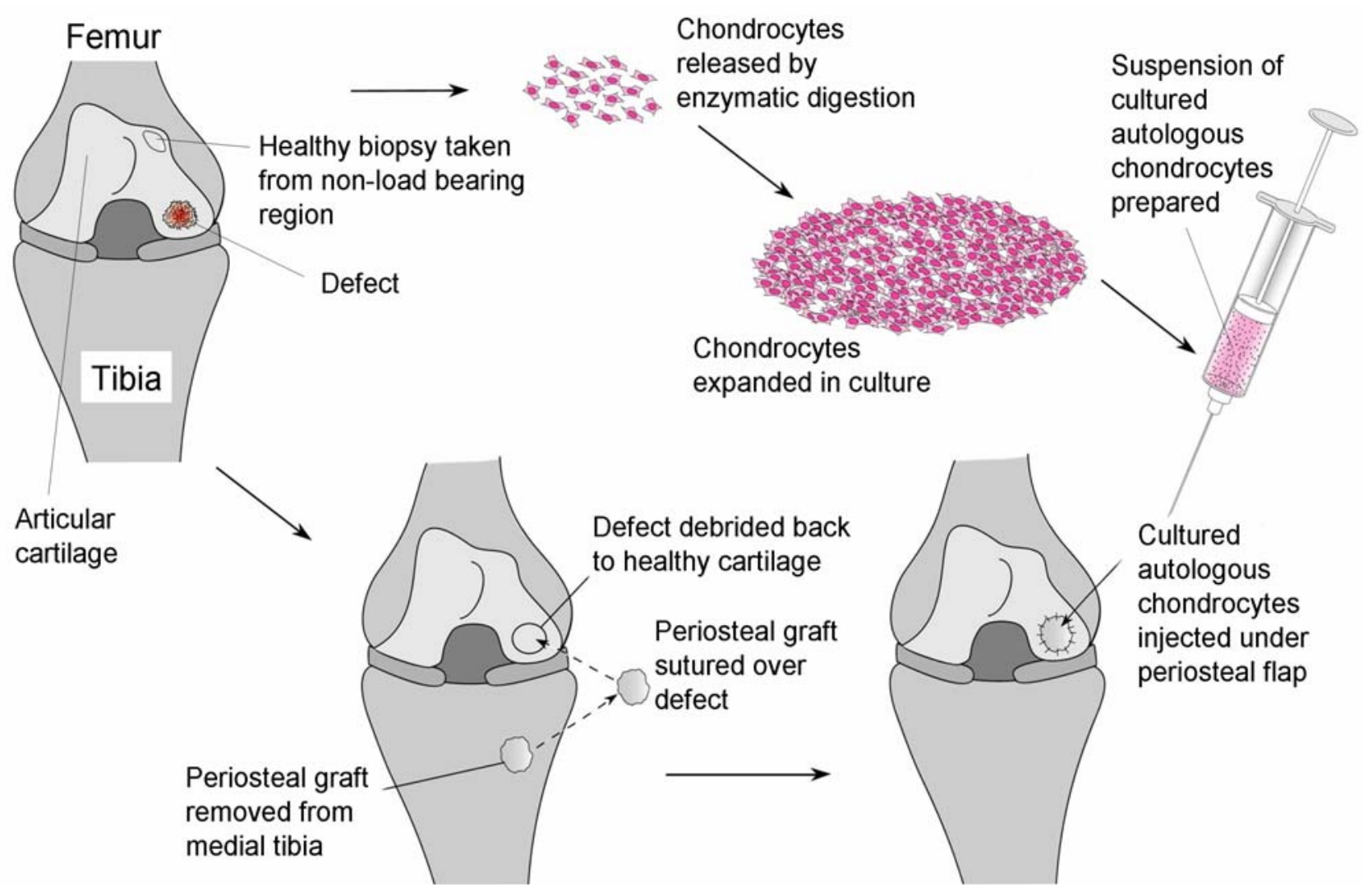

Figure 3. Schematic diagram showing the different stages involved in the process of autologous chondrocyte implantation.

symptomatic relief and is an established clinical technique, as to whether the autologous implanted chondrocytes themselves contribute to the overall structural integrity of the repair cartilage is poorly understood. Previous studies have proved controversial and have failed to elucidate the functional role of the implanted chondrocytes. In the canine model described previously by Breinan et al., (1997), implanted chondrocytes do not appear to be required for the proper repair of the cartilage defects, whereas absence of implanted autologous chondrocytes in the rabbit model leads to complete failure of the ACI procedure (Brittberg et al., 1996). Using a goat model, a recent study by Dell'Accio et al., (2003), assessed the structural contribution made by fluorescently labelled chondrocytes implanted into full-thickness cartilage defects in lateral femoral condyles. They reported that implanted cells are capable of participating in the formation of repair tissue denoted by collagen type II expression in the regions populated with the fluorescently tagged implanted chondrocytes and, furthermore, can persist in the defects for as long as 14 weeks post surgery. Whether these results represent a species difference remains to be determined.

\section{Scaffolds}

The use of matrix scaffolds in tissue engineering has paved the way for the use of functional tissue substitutes in the treatment of cartilage defects. Such scaffolds follow basic principles; they must be biocompatible, structurally and mechanically stable, must support the loading of an appropriate cell source to allow successful infiltration and attachment in conjunction with appropriate bioactive molecules in order to promote cellular differentiation and maturation. In a recent review of the current position of cartilage tissue engineering, Tuli et al., (2003) discussed two main types of scaffolds: natural and synthetic biomaterials, their methods of delivery and their suitability in the restoration of damaged cartilage.

Three-dimensional scaffolds are becoming increasingly popular due to the high standard of cellular attachment and mechanical stability that is achieved. Hyaluronan and collagen based matrices are among the most popular natural scaffolds as they offer a substrate that would normally be found in the structure of native articular cartilage. Preliminary clinical trials using a hyaluronan-based scaffold known as Hyalograft $\mathrm{C}^{\mathrm{TM}}$ have recently been conducted in the treatment of cartilage defects (Pavesio et al., 2003). Expanded autologous chondrocytes grown on the hyaluronan scaffolds are implanted into the cartilage defect without the need for a periosteal flap. Early clinical findings are encouraging, with $96.7 \%$ of repair tissue biologically acceptable with hyaline-like cartilage formation (Pavesio et al., 2003). Synthetic poly-a-hydroxy ester substrates in the form of polyglycolic (PGA) and poly(L)lactic (PLA) based scaffolds, however, have shown to enhance the promotion of proteoglycans, chondrocyte proliferation, differentiation and maturation in comparison to collagen based scaffolds (Grande et al., 1997). Whereas natural scaffolds may also face problems of immunogenic 
compatibility and batch inconsistency, it is evident that the properties offered by synthetic polyester matrices also provide much promise in the future of articular cartilage repair.

Although ACI has been performed successfully over the last decade, a new adapted approach based on this procedure has shown encouraging clinical results. Matrixinduced autologous chondrocyte implantation (MACI ${ }^{\mathrm{TM}}$ ) is now performed arthroscopically and allows the delivery of the patients own autologous chondrocytes into deep cartilage lesions using a collagen scaffold in place of a periosteal flap used in ACI (Bachmann et al., 2004; Behrens et al., 1999; Ronga et al., 2004). This procedure allows the seeding of chondrocytes onto a bilayer collagen I/III carrier membrane that is subsequently implanted into the cartilage defect and secured in place with fibrin glue. Chondrocytes are seeded on a porous surface that, when implanted, faces the bone to encourage tissue integration whilst a smooth surface acts as a natural barrier against soft tissue invasion (Vibe-Hansen and Aesculai, 1998). Using magnetic resonance imaging, results show hyalinecartilage formation and partial restoration of the articular surface in the defect site 12 months post-implantation (Ronga et al., 2004). In addition, studies have shown that this procedure is superior to microfracture with the rate of complete remission and the filling of the defect with regenerating tissue was higher in MACI treated lesions, with $85 \%$ of the defect filled 2 years after surgery (Bachmann et al., 2004).

\section{Chondrocyte Sub-Populations}

Clinical extrinsic repair strategies to date have predominantly focussed on the implantation of in vitro expanded full depth autologous chondrocytes (Brittberg et al., 1994). In the ongoing search to improve the functional properties of tissue-engineered cartilage, the use of specific chondrocyte populations are now being considered to investigate whether an improved cartilaginous structure would be generated by these specifically selected populations of chondrocytes. The potential role of the distinct phenotypic properties of chondrocytes, across the zones of articular cartilage for tissue engineering was demonstrated by Waldman et al., (2003). In this study, full-thickness, mid-and-deep zone and deep zone chondrocytes were isolated and seeded onto porous calcium phosphate substrates then cultured for 8 weeks. Results revealed that although collagen synthesis was highest in full-thickness chondrocytes, the combination of mid and deep zone articular chondrocytes provided far superior mechanical properties and the highest accumulation of proteoglycans. These findings suggest that if a combination of mid and deep zone chondrocytes were to replace the use of full-thickness articular chondrocytes in ACI for example, the repair tissue generated would be of a more superior standard and would, therefore, be more suitable for articular cartilage repair procedures. More recently Dowthwaite et al., (2004), have isolated and partially characterised a subpopulation of articular cartilage chondrocytes that reside in the superficial zone of immature bovine articular cartilage. These cells are believed to be a progenitor cell population thought to allow appositional growth of the articular cartilage from the articular surface (Hayes et al., 2001) and were isolated from the surface zone by exploiting their high affinity for fibronectin (Hynes, 1992). Phenotypic plasticity was tested by a series of in ovo injections where colony-derived populations of these chondroprogenitors were engrafted into a variety of connective tissue lineages thus confirming that this population of cells have properties akin to those of a progenitor cell. The high colony forming ability and the capacity to successfully expand these progenitor populations in vitro (Dowthwaite et al., 2004) may further aid our knowledge of cartilage development and growth and may provide novel solutions in the search for a successful therapy for treatment of articular cartilage defects.

\section{Mesenchymal Stem Cells}

If undifferentiated cells such as those identified in the surface zone of articular cartilage (Dowthwaite et al., 2004) may adapt our approach to future treatment of articular cartilage defects, we must consider the use of mesenchymal stem cells (MSCs) derived from other tissue sources besides cartilage, in these current repair strategies. MSCs are multipotent stem cells that have the ability to self-renew and intrinsically repair and regenerate the tissue in which they reside following damage or trauma. In addition, MSCs have the capacity to differentiate into a variety of other connective tissues such cartilage, bone, tendon, adipose tissue and muscle (Barry, 2003a; Barry, 2003b; Caplan, 1991; Gao and Caplan, 2003; Minguell et al., 2001; Pittenger et al., 1999; Prockop, 1997; Roufosse et al., 2004) and are characterised by the expression of specific cell surface markers (Arai et al., 2002; Barry et al., 1999; Lennon et al., 1995; Majumdar et al., 2000; Majumdar et al., 1998). Current research focuses mainly on methods to isolate and expand these cells in vitro, in order to improve the functional integrity of repair tissue by delivery either via carrier scaffolds or ACI in conjunction with specific active biomolecules such as growth factors to facilitate differentiation and maturation. Although human clinical trials are yet to be performed, the treatment of chondral defects with MSCs derived from alternative tissue sources other than cartilage have focussed mainly on the use of bone marrow-derived MSCs although other tissue sources such as the synovial membrane have also been considered.

A current review of the plasticity of bone marrowderived stem cells highlights the extensive capacity for these cells to differentiate along multiple tissue lineages (Grove et al., 2004). The rationale that bone marrow derived MSCs cells have the potential to facilitate osteochondral differentiation when implanted in vivo has long been realised (Ashhurst et al., 1990; Ashton et al., 1980; Friedenstein et al., 1987; Goshima et al., 1991), resulting in an interest in the use of these cells in cartilage tissue engineering (Wakitani et al., 1994). Until recently, however, optimal culture conditions to facilitate in vitro chondrogenesis of postnatal bone marrow-derived MSCs had not been established. Johnstone et al., (1998), reports that in vitro chondrogenesis of rabbit bone marrow-derived MSCs is achieved using a three-dimensional culture system in the presence of TGF- $\beta 1$. Studies in humans have also 
recently demonstrated the capacity of bone marrowderived MSCs to differentiate into a cartilage phenotype under appropriate culture conditions (Pittenger et al., 1999; Yoo et al., 1998). The characterisation and isolation of mesenchymal stem cells from human synovial membranes shows that a multipotential cell population resides within the tissue capable of inducing chondrogenesis under the appropriate conditions in vitro (De Bari et al., 2001). Furthermore, these clonally derived cells can be expanded extensively in culture whilst maintaining chondrogenic differentiation.

The phenotypic plasticity of human articular chondrocytes has to date been largely uncharacterised. Tallheden et al., (2003), reports that culture-expanded human articular chondrocytes present similar characteristics to that of a progenitor cell, however, they were unable to identify a specific progenitor cell population. More recently, Alsalameh et al., (2004), identified a potential MSC population within both normal and osteoarthritic human articular cartilage based upon specific CD marker expression. Although further characterisation in conjunction with the ability to clone and expand this progenitor cell population in vitro is sought, these data provide great promise for both intrinsic and extrinsic repair strategies in the restoration of damaged articular cartilage using native cartilage derived cells. Interestingly, a higher frequency of progenitor cells within osteoarthritic cartilage in comparison to normal articular cartilage was observed. This may indicate that either local recruitment from surrounding synovial tissues (MarinovaMutafchieva et al., 2000; Nishimura et al., 1999) or that MSCs residing in diseased tissue may be reverting back to a more immature phenotype.

\section{Conclusion}

The clinical goal of biological cartilage repair strategies is to provide symptomatic relief and improved joint function. Most of the repair strategies presented meet this aim, although, many fail to prevent future degeneration of the repair tissue and the surrounding host tissue. Degeneration is due, in part, to the nature of the repair tissue formed. The repair tissue is often of a fibrocartilaginous nature without the zonal organisation of articular cartilage. Where hyaline cartilage is produced, it is often of an immature nature and does not have a true articular surface. Functionally, the repair tissue may fail to withstand the mechanical demands of articular cartilage and combined with a lack of successful lateral integration between the host and repair tissue future degeneration is almost inevitable.

Future research may need to focus on a combination of biodegradable scaffolds and autologous cells to produce a mechanically functional hyaline repair tissue. Research also needs to focus upon promoting successful lateral integration between repair tissue and remaining cartilage. A combination of improved surgical instruments to minimise cell death at the wound margins and research to promote remodelling at the wound edge may enable successful predictable integration to occur.

\section{References}

Ahmad CS, Guiney WB, Drinkwater CJ (2002) Evaluation of donor site intrinsic healing response in autologous osteochondral grafting of the knee. Arthroscopy 18: 95-98.

Akizuki S, Yasukawa Y, Takizawa T (1997) Does arthroscopic abrasion arthroplasty promote cartilage regeneration in osteoarthritic knees with eburnation? A prospective study of high tibial osteotomy with abrasion arthroplasty versus high tibial osteotomy alone. Arthroscopy 13: 9-17.

Alfredson H, Lorentzon R (1999) Superior results with continuous passive motion compared to active motion after periosteal transplantation. A retrospective study of human patella cartilage defect treatment. Knee Surg Sports Traumatol Arthrosc 7: 232-238.

Alsalameh S, Amin R, Gemba T, Lotz M (2004) Identification of mesenchymal progenitor cells in normal and osteoarthritic human articular cartilage. Arthritis Rheum 50: 1522-1532.

Arai F, Ohneda O, Miyamoto T, Zhang XQ, Suda T (2002) Mesenchymal stem cells in perichondrium express activated leukocyte cell adhesion molecule and participate in bone marrow formation. J Exp Med 195: 1549-1563.

Ashhurst DE, Ashton BA, Owen ME (1990) The collagens and glycosaminoglycans of the extracellular matrices secreted by bone marrow stromal cells cultured in vivo in diffusion chambers. J Orthop Res 8: 741-749.

Ashton BA, Allen TD, Howlett CR, Eaglesom CC, Hattori A, Owen M (1980) Formation of bone and cartilage by marrow stromal cells in diffusion chambers in vivo. Clin Orthop 151: 294-307.

Bachmann G, Basad E, Lommel D, Steinmeyer J (2004) MRI in the follow-up of matrix-supported autologous chondrocyte transplantation (MACI) and microfracture. Radiologe 44: 773-782.

Barry FP (2003a) Biology and clinical applications of mesenchymal stem cells. Birth Defects Res C Embryo Today 69: 250-256.

Barry FP (2003b) Mesenchymal stem cell therapy in joint disease. Novartis Found Symp 249: 86-96; discussion 96-102, 170-104, 239-141.

Barry FP, Boynton RE, Haynesworth S, Murphy JM., Zaia J (1999) The monoclonal antibody SH-2, raised against human mesenchymal stem cells, recognizes an epitope on endoglin (CD105). Biochem Biophys Res Commun 265: 134-139.

Behrens P, Ehlers EM, Kochermann KU, Rohwedel J, Russlies M, Plotz W (1999) New therapy procedure for localized cartilage defects. Encouraging results with autologous chondrocyte implantation. MMW Fortschr Med 141: 49-51.

Beiser IH, Kanat IO (1990) Subchondral bone drilling: a treatment for cartilage defects. J Foot Surg 29: 595-601.

Bobic V (1999) Osteochondral autologous graft transplantation in the treatment of focal articular cartilage lesions. Seminars in Arthroplasty 10: 21-29.

Breinan HA, Minas T, Hsu HP, Nehrer S, Shortkroff S, Spector M (2001) Autologous chondrocyte implantation 
in a canine model: change in composition of reparative tissue with time. J Orthop Res 19: 482-492.

Breinan HA, Minas T, Hsu HP, Nehrer S, Sledge CB, Spector M (1997) Effect of cultured autologous chondrocytes on repair of chondral defects in a canine model. J Bone Joint Surg Am 79: 1439-1451.

Brittberg M (1999) Autologous chondrocyte transplantation. Clin Orthop 367: S147-155.

Brittberg M, Lindahl A, Nilsson A, Ohlsson C, Isaksson O, Peterson L (1994) Treatment of deep cartilage defects in the knee with autologous chondrocyte transplantation. N Engl J Med 331: 889-895.

Brittberg M, Nilsson A, Lindahl A, Ohlsson C, Peterson L (1996) Rabbit articular cartilage defects treated with autologous cultured chondrocytes. Clin Orthop 326: 270 283.

Caplan AI (1991) Mesenchymal stem cells. J Orthop Res 9: 641-650.

Carranza-Bencano A, Garcia-Paino L, Armas Padron JR, Cayuela Dominguez A (2000) Neochondrogenesis in repair of full-thickness articular cartilage defects using free autogenous periosteal grafts in the rabbit. A follow-up in six months. Osteoarthritis Cartilage 8: 351-358.

Carranza-Bencano A, Perez-Tinao M, BallesterosVazquez P, Armas-Padron JR, Hevia-Alonso A, Martos Crespo F (1999) Comparative study of the reconstruction of articular cartilage defects with free costal perichondrial grafts and free tibial periosteal grafts: an experimental study on rabbits. Calcif Tissue Int 65: 402-407.

Chang RW, Falconer J, Stulberg SD, Arnold WJ, Manheim LM, Dyer AR (1993) A randomized, controlled trial of arthroscopic surgery versus closed-needle joint lavage for patients with osteoarthritis of the knee. Arthritis Rheum 36: 289-296.

Czitrom AA, Langer F, McKee N, Gross AE (1986) Bone and cartilage allotransplantation. A review of 14 years of research and clinical studies. Clin Orthop 208: 141145.

De Bari C, Dell'Accio F, Tylzanowski P, Luyten FP (2001) Multipotent mesenchymal stem cells from adult human synovial membrane. Arthritis Rheum 44: 19281942.

Dell'Accio F, Vanlauwe J, Bellemans J, Neys J, De Bari C, Luyten FP (2003) Expanded phenotypically stable chondrocytes persist in the repair tissue and contribute to cartilage matrix formation and structural integration in a goat model of autologous chondrocyte implantation. J Orthop Res 21: 123-131.

Dowthwaite GP, Bishop JC, Redman SN, Khan IM, Rooney P, Evans DJ, Haughton L, Bayram Z, Boyer S, Thomson B, Wolfe MS, Archer CW (2004) The surface of articular cartilage contains a progenitor cell population. J Cell Sci 117: 889-897.

Evans PJ, Miniaci A, Hurtig MB (2004) Manual punch versus power harvesting of osteochondral grafts. Arthroscopy 20: 306-310.

Friedenstein AJ, Chailakhyan RK, Gerasimov UV (1987) Bone marrow osteogenic stem cells: in vitro cultivation and transplantation in diffusion chambers. Cell Tissue Kinet 20: 263-272.
Gao J, Caplan AI (2003) Mesenchymal stem cells and tissue engineering for orthopaedic surgery. Chir Organi Mov 88: 305-316.

Goshima J, Goldberg VM, Caplan AI (1991) Osteogenic potential of culture-expanded rat marrow cells as assayed in vivo with porous calcium phosphate ceramic. Biomaterials 12: 253-258.

Grande DA, Halberstadt C, Naughton G, Schwartz R, Manji R (1997) Evaluation of matrix scaffolds for tissue engineering of articular cartilage grafts. J Biomed Mater Res 34: 211-220.

Grove JE, Bruscia E, Krause DS (2004) Plasticity of bone marrow-derived stem cells. Stem Cells 22: 487-500.

Hangody L, Kish G, Karpati Z, Szerb I, Udvarhelyi I (1997) Arthroscopic autogenous osteochondral mosaicplasty for the treatment of femoral condylar articular defects. A preliminary report. Knee Surg Sports Traumatol Arthrosc 5: 262-267.

Hangody, L., Kish, G., Karpati, Z., Udvarhelyi, I., Szigeti, I., and Bely, M. (1998). Mosaicplasty for the treatment of articular cartilage defects: application in clinical practice. Orthopedics 21, 751-756.

Hangody L, Rathonyi GK, Duska Z, Vasarhelyi G, Fules P, Modis L (2004) Autologous osteochondral mosaicplasty. Surgical technique. J Bone Joint Surg Am 86-A Suppl 1: 65-72.

Hayes AJ, MacPherson S, Morrison H, Dowthwaite G, Archer CW (2001) The development of articular cartilage: evidence for an appositional growth mechanism. Anat Embryol (Berl) 203: 469-479.

Hunt SA, Jazrawi LM, Sherman OH (2002) Arthroscopic management of osteoarthritis of the knee. J Am Acad Orthop Surg 10: 356-363.

Hunziker EB (2001) Growth-factor-induced healing of partial-thickness defects in adult articular cartilage. Osteoarthritis Cartilage 9: 22-32.

Hunziker EB, Rosenberg LC (1996) Repair of partialthickness defects in articular cartilage: cell recruitment from the synovial membrane. J Bone Joint Surg Am 78: 721-733.

Hynes RO (1992) Integrins: versatility, modulation, and signaling in cell adhesion. Cell 69: 11-25.

Insall J (1974) The Pridie debridement operation for osteoarthritis of the knee. Clin Orthop 101: 61-67.

Ito Y, Fitzsimmons JS, Sanyal A, Mello MA, Mukherjee N, O'Driscoll SW (2001) Localization of chondrocyte precursors in periosteum. Osteoarthritis Cartilage 9: 215 223.

Jackson RW, Dieterichs C (2003) The results of arthroscopic lavage and debridement of osteoarthritic knees based on the severity of degeneration: a 4- to 6-year symptomatic follow-up. Arthroscopy 19: 13-20.

Jakob RP, Franz T, Gautier E, Mainil-Varlet P (2002) Autologous osteochondral grafting in the knee: indication, results, and reflections. Clin Orthop 401: 170-184.

Johnson LL (2001) Arthroscopic abrasion arthroplasty: a review. Clin Orthop 391: S306-317.

Johnstone B, Hering TM, Caplan AI, Goldberg VM, Yoo JU (1998) In vitro chondrogenesis of bone marrowderived mesenchymal progenitor cells. Exp Cell Res 238: 265-272. 
Korkala OL, Kuokkanen HO (1995) Autoarthroplasty of knee cartilage defects by osteoperiosteal grafts. Arch Orthop Trauma Surg 114: 253-256.

Langer F, Gross AE, West M, Urovitz EP (1978) The immunogenicity of allograft knee joint transplants. Clin Orthop 132: 155-162.

LaPrade RF, Botker JC (2004) Donor-site morbidity after osteochondral autograft transfer procedures. Arthroscopy 20: e69-73.

Lennon DP, Haynesworth SE, Young RG, Dennis JE, Caplan AI (1995) A chemically defined medium supports in vitro proliferation and maintains the osteochondral potential of rat marrow-derived mesenchymal stem cells. Exp Cell Res 219: 211-222.

Livesley PJ, Doherty M, Needoff M, Moulton A (1991) Arthroscopic lavage of osteoarthritic knees. J Bone Joint Surg Br 73: 922-926.

Lorentzon R, Alfredson H, Hildingsson C (1998) Treatment of deep cartilage defects of the patella with periosteal transplantation. Knee Surg Sports Traumatol Arthrosc 6: 202-208.

Majumdar MK, Thiede MA, Haynesworth SE, Bruder SP,Gerson SL (2000) Human marrow-derived mesenchymal stem cells (MSCs) express hematopoietic cytokines and support long-term hematopoiesis when differentiated toward stromal and osteogenic lineages. J Hematother Stem Cell Res 9: 841-848.

Majumdar MK, Thiede MA, Mosca JD, Moorman M, Gerson SL (1998) Phenotypic and functional comparison of cultures of marrow-derived mesenchymal stem cells (MSCs) and stromal cells. J Cell Physiol 176: 57-66.

Mankin HJ (1982) The response of articular cartilage to mechanical injury. J Bone Joint Surg Am 64: 460-466.

Marinova-Mutafchieva L, Taylor P, Funa K, Maini RN, Zvaifler NJ (2000) Mesenchymal cells expressing bone morphogenetic protein receptors are present in the rheumatoid arthritis joint. Arthritis Rheum 43: 2046-2055.

Micheli LJ, Browne JE, Erggelet C, Fu F, Mandelbaum B, Moseley JB, Zurakowski, D. (2001). Autologous chondrocyte implantation of the knee: multicenter experience and minimum 3-year follow-up. Clin J Sport Med 11: 223-228.

Minas T (1998) Chondrocyte implantation in the repair of chondral lesions of the knee: economics and quality of life. Am J Orthop 27: 739-744.

Minguell JJ, Erices A, Conget P (2001) Mesenchymal stem cells. Exp Biol Med (Maywood) 226: 507-520.

Moseley JB, O’Malley K, Petersen NJ, Menke TJ, Brody BA, Kuykendall DH, Hollingsworth JC, Ashton CM, Wray NP (2003) Arthroscopic lavage or debridement did not reduce pain more than placebo did in patients with osteoarthritis. J Bone Joint Surg Am 85-A: 387.

Namba RS, Meuli M, Sullivan KM, Le AX, Adzick NS (1998) Spontaneous repair of superficial defects in articular cartilage in a fetal lamb model. J Bone Joint Surg Am 80: 4-10.

Nishimura K, Solchaga LA, Caplan AI, Yoo JU, Goldberg VM, Johnstone B (1999) Chondroprogenitor cells of synovial tissue. Arthritis Rheum 42: 2631-2637.

O’Driscoll SW (1999) Articular cartilage regeneration using periosteum. Clin Orthop 367: S186-203.
Pavesio A, Abatangelo G, Borrione A, Brocchetta D, Hollander AP, Kon E, Torasso F, Zanasi S, Marcacci M (2003) Hyaluronan-based scaffolds (Hyalograft C) in the treatment of knee cartilage defects: preliminary clinical findings. Novartis Found Symp 249: 203-217; discussion 229-233, 234-208, 239-241.

Peterson L, Minas T, Brittberg M, Nilsson A, SjogrenJansson E, Lindahl A (2000) Two- to 9-year outcome after autologous chondrocyte transplantation of the knee. Clin Orthop 374: 212-234.

Pittenger MF, Mackay AM, Beck SC, Jaiswal RK, Douglas R, Mosca JD, Moorman MA, Simonetti DW, Craig S, Marshak DR (1999) Multilineage potential of adult human mesenchymal stem cells. Science 284: 143147.

Prockop DJ (1997) Marrow stromal cells as stem cells for nonhematopoietic tissues. Science 276: 71-74.

Ronga M, Grassi FA, Bulgheroni P (2004) Arthroscopic autologous chondrocyte implantation for the treatment of a chondral defect in the tibial plateau of the knee. Arthroscopy 20: 79-84.

Roufosse CA, Direkze NC, Otto WR, Wright NA (2004) Circulating mesenchymal stem cells. Int J Biochem Cell Biol 36: 585-597.

Shannon FJ, Devitt AT, Poynton AR, Fitzpatrick P, Walsh MG (2001) Short-term benefit of arthroscopic washout in degenerative arthritis of the knee. Int Orthop 25: 242-245.

Shapiro F, Koide S, Glimcher MJ (1993) Cell origin and differentiation in the repair of full-thickness defects of articular cartilage. J Bone Joint Surg Am 75: 532-553.

Simonian PT, Sussmann PS, Wickiewicz TL, Paletta GA, Warren RF (1998) Contact pressures at osteochondral donor sites in the knee. Am J Sports Med 26: 491-494.

Singh S, Lee CC, Tay BK (1991) Results of arthroscopic abrasion arthroplasty in osteoarthritis of the knee joint. Singapore Med J 32: 34-37.

Sledge SL (2001) Microfracture techniques in the treatment of osteochondral injuries. Clin Sports Med 20: 365-377.

Steadman JR, Briggs KK, Rodrigo JJ, Kocher MS, Gill TJ, Rodkey WG (2003) Outcomes of microfracture for traumatic chondral defects of the knee: average 11-year follow-up. Arthroscopy 19: 477-484.

Stevenson S (1987) The immune response to osteochondral allografts in dogs. J Bone Joint Surg Am 69: 573-582.

Tallheden T, Dennis JE, Lennon DP, Sjogren-Jansson E, Caplan AI, Lindahl A (2003) Phenotypic plasticity of human articular chondrocytes. J Bone Joint Surg Am 85A: Suppl 2, 93-100.

Tomford WW, Springfield DS, Mankin HJ (1992) Fresh and frozen articular cartilage allografts. Orthopedics 15: 1183-1188.

Tuli R, Li WJ, Tuan RS (2003) Current state of cartilage tissue engineering. Arthritis Res Ther 5: 235-238.

Vibe-Hansen R, Aesculai S (1998) Methods, instruments and kit for autologous chondrocyte transplantation. Patent WO 98/08469.

Wakitani S, Goto T, Pineda SJ, Young RG, Mansour JM, Caplan AI, Goldberg VM (1994) Mesenchymal cell- 
based repair of large, full-thickness defects of articular cartilage. J Bone Joint Surg Am 76: 579-592.

Waldman SD, Grynpas MD, Pilliar RM, Kandel RA (2003) The use of specific chondrocyte populations to modulate the properties of tissue-engineered cartilage. J Orthop Res 21: 132-138.

Yoo JU, Barthel TS, Nishimura K, Solchaga L, Caplan AI, Goldberg VM, Johnstone B (1998) The chondrogenic potential of human bone-marrow-derived mesenchymal progenitor cells. J Bone Joint Surg Am 80: 1745-1757.

Zarnett R, Salter RB (1989) Periosteal neochondrogenesis for biologically resurfacing joints: its cellular origin. Can J Surg 32: 171-174.

\section{Discussion with Reviewers}

PJ. Roughley: Does the cartilage matrix produced by cell based repair techniques have the same structural and mechanical properties as the mature cartilage in the joint? If not, is this detrimental to tissue function and a harbinger of subsequent degeneration? If so can anything be done to speed up the maturation process?

Authors: The cartilage matrix produced by cell based repair techniques, even where 'hyaline-like' repair tissue is formed, is of an immature nature and, as such, lacks the structural and mechanical properties of mature cartilage. Under normal loading conditions, this may well lead to the future degeneration of the repair tissue. The authors feel that it is important to achieve successful lateral integration between the repair tissue and the host cartilage, currently the one area where all repair procedures fail. There is speculation that repair tissue matures from the base upwards, if degeneration of the tissue can be prevented, with time, further maturation of the repair tissue may lead to a true articular surface. Successful integration may provide more stability to the repair tissue which may allow the repair tissue to mature and attain functional properties similar to articular cartilage.
C. Lee: As discussed, it is clear that the current repair strategies do not satisfactorily regenerate normal articular cartilage (histologically, mechanically, integratively), yet there is a high clinical success rate. Do you think it is just a matter of time before the sub-optimal repair becomes a problem or do you think it somehow is good enough for normal healthy joint function? In other words, do we really need to keep working on developing "better" treatments? Authors: As discussed, most of the repair strategies currently employed provide symptomatic relief. This symptomatic relief should always be the ultimate goal of cartilage repair procedures not necessarily a histologically accurate repair tissue biopsy. It should be borne in mind, however, that with time repair tissue degenerates which, as a consequence, may give rise to further degeneration of the host cartilage. As researchers, we should strive to develop "better" treatments, to produce a more mechanically functional repair tissue that integrates successfully and predictably with the host articular cartilage.

C. Lee: What are the current limitations for the reviewed techniques in terms of defect size and overall health of the rest of the joint (i.e. ligament or meniscus damage?). Authors: The clinical outcome of repair procedures, while varied, is often inversely related to the size of the defect treated. Clinically, however, with improved surgical technique larger defects may be treated successfully. For example, repair of the entire femoral condyle using autologous chondrocytes seeded under a collagen membrane has been carried out successfully (personal communication Prof. James Richardson). It should be considered whether the repair procedure is to be carried out by arthroscopy or arthrotomy. Procedures carried out by arthroscopy reduce the damage to other joint tissues such as tendons and ligaments. Refinement of surgical techniques should reduce the need for arthrotomic procedures, i.e. MACI which is similar to ACI, utilises a collagen membrane rather than a periosteal flap and may be carried out by arthroscopy rather than the current arthrotomic procedure (Ronga et al, 2004). 